\title{
Publication trends in Naunyn-Schmiedeberg's Archives of Pharmacology: focus on pharmacology in Egypt
}

\author{
Mahmoud M. El-Mas • Hanan M. El-Gowelli • \\ Martin C. Michel
}

Received: 2 September 2013 / Accepted: 4 September 2013 /Published online: 14 September 2013

(C) Springer-Verlag Berlin Heidelberg 2013

\begin{abstract}
In a previous analysis of the country of origin of papers published in Naunyn-Schmiedeberg's Archives of Pharmacology, a major shift toward contributions from emerging market countries, was noticed in comparison of 2010 to 2001 publications. Repeating such analysis for 2012 publications in the journal confirmed this trend. An interesting new trend was the emerging presence of papers from a variety of Islamic countries including Egypt. Based on this trend, we shortly review the history and current structure of pharmacology in Egypt. It appears that the presence of Egyptian pharmacology in international journals including pharmacology journals has sharply been increasing over the last two decades. Challenges for a continuation of this encouraging trend are being discussed.
\end{abstract}

In 2011, we reported an analysis of the countries of origin of papers published in Naunyn-Schmiedeberg's Archives of Pharmacology in 2010 as compared to 2001 (Coelho et al. 2011). At the time, we noted that in the course of a decade, countries of authorship of papers published in the journal had shifted from Western Europe to Asia, Latin America, and Eastern Europe. At the time, we found it specifically noteworthy that Brazil had turned from a country being hardly present in the journal to one of the most frequent ones. Two years later, we have revisited this issue by looking at papers published in the journal in 2012 (Fig. 1). Our analysis shows that the trend for international diversification of authorship

M. M. El-Mas · H. M. El-Gowelli

Department of Pharmacology and Toxicology, Faculty of Pharmacy, Alexandria University, Alexandria, Egypt

M. C. Michel $(\bowtie)$

Department of Pharmacology, Johannes Gutenberg University,

Obere Zahlbacher Str. 67, 55101 Mainz, Germany

e-mail: marmiche@uni-mainz.de continues; specifically, Brazil continues to be a strong country in publishing in the journal.

In our 2012 analysis, another trend was noted. Historically, the Arab world has been one of the cradles of science, and Islamic countries have held a leadership role in science for centuries. However, their contribution to science had been surpassed by Western countries in more recent centuries, a trend that was also noticeable in international pharmacology journals including Naunyn-Schmiedeberg's Archives of Pharmacology, where Islamic countries were almost absent in our 2001 and 2010 analysis. Therefore, it was very interesting to see that our analysis of the 2012 publications showed a considerable group of papers from Islamic countries, accounting for about $6 \%$ of all papers published in the journal in that year. Interestingly, this did not result from one specific country contributing a major number of papers, but rather from a range of countries contributing one or two papers. These included Arab countries such as Egypt and Kuwait as well as non-Arab countries such as Iran, Turkey, and Malaysia. Countries which had contributed little to the journal in the past also included non-Islamic countries such as Ukraine (Votychik et al. 2012) and Croatia (Jembrek et al. 2012). This regional diversification in authorship is highly welcomed by the journal. It appears to reflect a general trend in international scientific publications, as e.g., Saudi Arabia has shown one of the largest relative increases in publications in international scientific journals in 2012 (van Noorden 2012).

When we previously looked at the topics of a key interest to Brazilian pharmacologists as published in Naunyn-Schmiedeberg's Archives of Pharmacology, we found a strong emphasis on pain and inflammation and on natural products, the latter reflecting the rich biodiversity in Brazil (Coelho et al. 2011). In contrast, the papers coming from Islamic countries typically have not focused on natural products, but rather on chemically defined substances. Moreover, they represent a broad range of topics such as ischemia/reperfusion injury (Hosseinzadeh et al. 2012; 

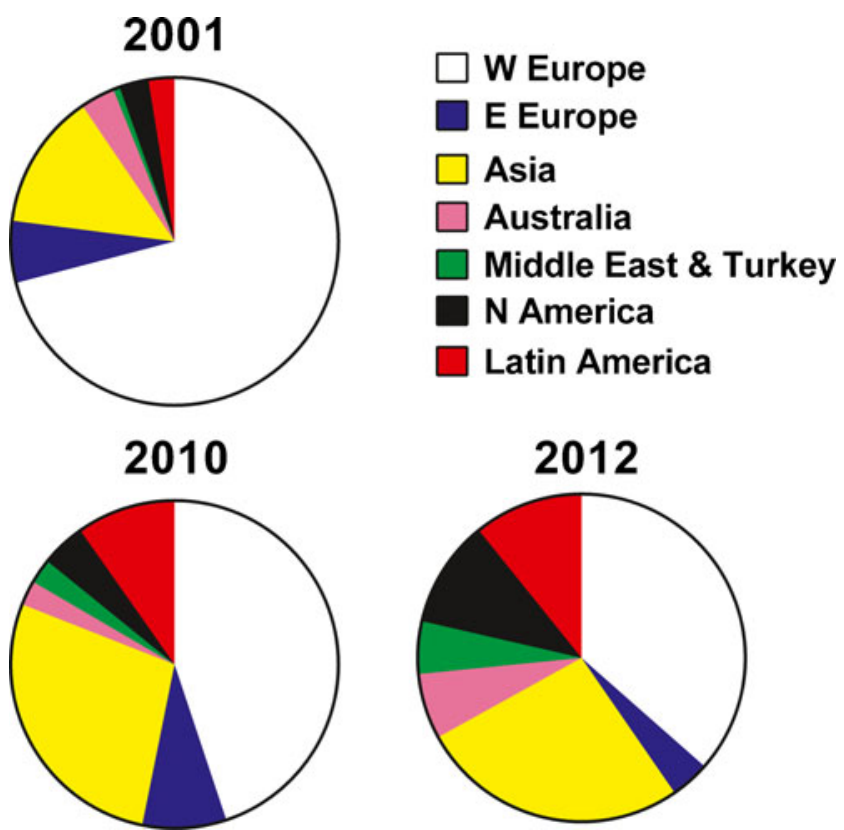

Fig. 1 Relative contributions of various parts of the world to papers published in Naunyn-Schmiedeberg's Archives of Pharmacology in 2001, 2010, and 2012. Each pie slice represents the percentage of the indicated region of all papers published in the journal in that calendar year

Mahmoud et al. 2012), atrial fibrillation (Khori et al. 2012), allergic airway disease (Nader et al. 2012), skeletal muscle (Hosseinzadeh et al. 2012; Renno et al. 2012), urinary bladder smooth muscle (Balkanci et al. 2012), or the metabolism of xenobiotics (Pang et al. 2012).

While authorship from Turkey may not be surprising, given that this country had a very dynamic economy in recent years, scientists in some of the other abovenamed countries face a considerable hardship, as e.g., scientists in Iran continue to experience difficulties in getting access to modern reagents. Moreover, several Arab countries have undergone major changes in the last few years. Therefore, we wish to describe specifically the experience of Egyptian pharmacologists in a country undergoing rapid changes.

Pharmacological knowledge of ancient Egypt recorded in various papyri was the earliest known in human history, and the most important of which is the Ebers Papyrus (1500 BC) discovered by the German Egyptologist Georg Ebers at Luxor (Thebes) in 1872 and is now in the Library of the University of Leipzig in Germany. The other papyrus is the Edwin Smith Papyrus (1700 BC), which was the first papyrus to present a rational and scientific approach to medicine in the known history (Haas 1999). Many centuries later, medicine was a central part of Islamic culture. The invention of "hospitals" was one of the greatest achievements of Islamic medicine. In Egypt, the first hospital was built in Cairo in $872 \mathrm{AD}$ by Ahmad ibn Tulun, the governor of Egypt. In the twelfth century, the Mansuri Hospital was completed, which remained the primary medical center in Cairo through the fifteenth century and helped along with the other hospitals to achieve great advances and discoveries in medical sciences. With the fragmentation of the Islamic world by the end of the sixteenth century, the practice of medicine deteriorated, and the Islamic medicine then became receptive to some of the ideas, techniques, and drug therapies that had developed in Europe (Savage-Smith 1994).

In 1908, the Cairo University was founded, and medical sciences started to flourish again in Egypt. The Cairo University included a school of medicine known till now as "Kasr Alaini," which was one of the first medical schools in Africa and the Middle East. This school was the leading entity for medical research and education in the Middle East (Reid 1990). Indeed, the presence of many prestigious professors from all over the world in the 1930s and 1940s of the twentieth century in the Cairo University helped in establishing the basis for pharmacological research in Egypt. For instance, Sir Horace Smirk, the father of the modern treatment of hypertension, through his introduction of the quaternary ammonium ganglion-blocking drugs for malignant hypertension, was a professor of pharmacology at the Egyptian University in Cairo in the 1930s (Dollery 2006). However, since the late 1960s, the Egyptian universities became underfunded and overcrowded, which seriously affected the quality of all fields of education and research (Reid 1990).

One milestone that markedly contributed to the advancement of pharmacological research in Egypt was the establishment of the Egyptian Society of Pharmacology and Experimental Therapeutics (ESPET), a member of the International Union of Pharmacology (IUPHAR). ESPET has been founded in 1957 by the late Prof. Khayyal MA, Chair of the Department of Pharmacology, Faculty of Medicine, Cairo University. When first founded, the society was affiliated to the Egyptian Medical Association but became an independent society in the mid1970s. It comprised only few pharmacologists at the time but has grown rapidly ever since, and now it encompasses hundreds of basic and clinical pharmacologists. ESPET organizes an annual scientific conference in which known Egyptian and regional pharmacologists are invited to give lectures on diverse pharmacological themes. This event is also attended by Egyptian pharmacologists coming from different laboratories from all over the world, which helps in communicating new ideas and research trends.

Nowadays in Egypt, pharmacology departments are present in the faculties of medicine, pharmacy, and veterinary medicine in different universities. Remarkably, ten pharmacy programs have been started in the Middle East since the year 2000 , and the majority of these appear to be private institutions. The total number of pharmacy schools in Egypt approached 24 (13 public and 11 private) (Kheir et al. 2008). There are numerous graduate programs in pharmacology in the faculties of pharmacy (24), medicine (21), and veterinary medicine (12), and most of them are training Master and Ph.D. 
students from Egypt and many other countries. In addition to these graduate programs in pharmacology, there are programs in biochemistry, physiology, and pharmaceutical sciences in which researchers contribute to pharmacological research.

According to the data collected from the "Thomson Reuters Web of Knowledge," the number of scientific papers published in international journals from Egyptian universities and research institutes showed progressive increases over the last 40 years. In 1980, for example, the total number of publications in international journals from all scientific disciplines amounted to 1,739. As shown in Fig. 2, this number was almost doubled every 10 years since then with the number of publications approaching 13,000 in 2012. A similar trend of progressive increases in scientific publications was also noted in the area of "pharmacological" with a total of 860 research papers published in 2012 (Fig. 2). It is worth noting that a significant number of Egyptian pharmacological papers are not published in international journals, but they appear in domestic scientific journals that are not abstracted or indexed with international indexing systems because they deal mostly with the biological effects of the Egyptian natural products that lack standardization.

It is imperative to comment on possible grounds for the progress in the research productivity achieved by Egyptian institutions. One important landmark might relate to the move taken by the Egyptian Ministry for Higher Education and Scientific Research in 2006 to overhaul the science and technology sectors in Egypt and to introduce drastic changes into the management system of scientific research. A presidential decree was issued to create the Higher Council for Science and Technology (HCST) and the Science and Technological Development Fund (STDF). Of particular importance, the
STDF (http://www.stdf.org.eg/) was authorized to fund national scientific research according to priorities proposed by the HCST. These reforms led to an encouragement of scientific research and international publications in different fields of science including medicine and pharmacology. The STDF sponsors a variety of national grants including the basic and applied research grant, the young research grants, reintegration grants, innovation grants, and targeted calls. The STDF also funds and oversees international collaborative grants between Egyptian scholars and their international counterparts from countries such as the USA, Germany, France, Japan, and Italy.

In 2007, the National Authority for Quality Assurance and Accreditation of Education in Egypt (NAQAAE) was established. The NAQAAE is an independent agency working on developing quality assurance and accreditation standards for various types of education. It is the accrediting body for all Egyptian educational institutions. This has led to the upgrading of the laboratories' infrastructure and instrumentations nationwide, which was reflected, both quantitatively and qualitatively, on all research fields in Egypt including pharmacology. Notably, the country ranking of Egypt in the area of pharmacology, toxicology, and pharmaceutics in the year 2006 was the 34th with a total of 211 published citable documents. By the years 2010 and 2011, Egypt came in the 23rd place with a total of 401 and 463 published citable documents, respectively, as mentioned in the SCImago Journal \& Country Rank developed from the information contained in the Scopus ${ }^{\circledR}$ database. On the other hand, Turkey came in the 20th place in 2006 and in the 21st place in 2010 and 2011 with a total of 467, 491, and 532 published citable documents, respectively.

Since the 1970s, the promotion of faculty members in Egyptian universities and research institutes to higher academic
Fig. 2 The number of scientific papers published in international journals from Egyptian universities and research institutes over the last 40 years (source: Thomson Reuters Web of Knowledge based on the search terms "address: Egypt" and "topic: pharmacology")

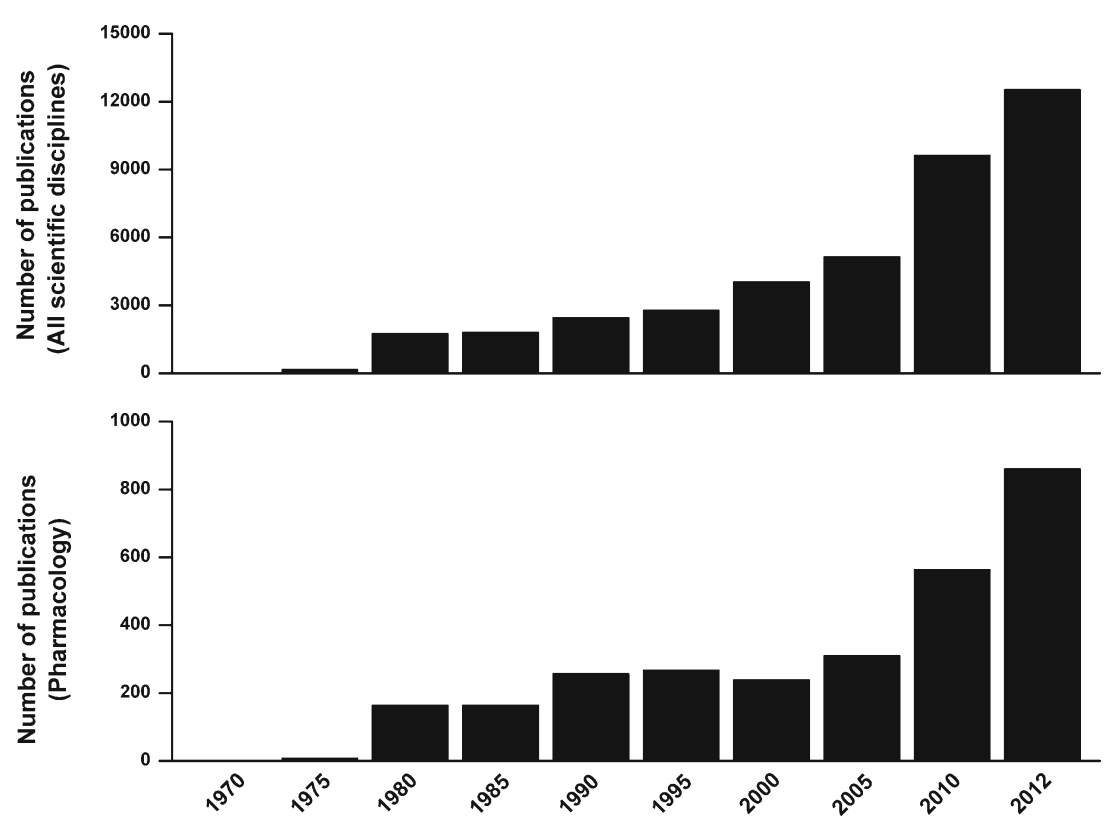


ranks (associate and full professorship) was determined by national committees in all scientific fields. Members of the national promotion committees are selected periodically by the Supreme Council of Egyptian Universities (http://www.scu.eun.eg/wps/ portal) based on scientific qualities and credentials. The national promotion committee for pharmacology has worked closely with other scientific bodies in the field to improve the quality of pharmacological research in Egypt. Over the last 5 years, the committee has revised its rules so as to put more emphasis on the importance of international publications in journals with high impact factors as one basic criterion for academic promotion. Other qualifications include teaching and societal activities, the attendance of international conferences, the winning of national and international awards, and receiving grant funds.

All international systems for ranking world universities adopt published papers in top-ranking journals as a major determinant of the ranking. This pushed the Egyptian Ministry of Higher Education and Research, the Supreme Council of Egyptian Universities, and Egyptian institutions to stress on the importance of publishing research papers in top-rated scientific journals. Therefore, researchers now in Egypt appreciate the significance of the journal impact factors and citation metrics (e.g., $h$ index and citation index) in their academic career and promotion as well as for receiving national, regional, and international awards and many other things.

With that said, we feel it necessary to elaborate on potential obstacles and challenges for research progress and development in Egypt. Despite recent advances in the research environment and capabilities in Egyptian institutions in different scientific modalities including pharmacology, Egypt, like many other Middle Eastern countries, still lags behind other regions of the world in terms of funding research and technological development and innovation. Since the eruption of the revolution on January 25, 2011, there has been a lot of pressure on the Egyptian government to increase the annual research budget. Over the following 2 years, the research budget rose from 0.25 to $0.4 \%$ of GDP. As it stands, the research budget is still too low compared with the average research fund in developed and industrialized nations ( $3-5 \%$ of GDP). Along the same point, the contribution of the private sector, industries, and pharmaceutical firms to pharmacological research and drug technology is far below expectation. Other impeding factors include the complexity and inflexibility of bureaucratic rules in governmental and institutional practices, which limits national growth and development in all sectors of life including scientific research. Indeed, the elimination of unnecessary bureaucracy is a key element for managerial success. A third weakness of scientific research in Egypt, which is a logic consequence to all of the above, pertains to the fact that papers are mostly descriptive and lack deep insights and cellular and molecular approaches. Understandably, this may account for the fact that most of the papers from
Egyptian institutions are published in journals with low to intermediate impact factors, with only few if any published in the world most prestigious journals, e.g., Science and Nature.

In summary, the importance of scientific research stems from the fact that it produces knowledge that improves and enriches the quality of our life. As far as medical and pharmacological research is concerned, it is believed that today's research is tomorrow's cure. As detailed earlier, while several factors have contributed to some sensible expansion in pharmacological research in Egypt over the last four decades, more governmental and institutional efforts are required to achieve more progress. Indeed, the future of pharmacological research in Egypt is promising due to the abundance of dedicated and qualified scholars and the continuous training of young researchers. We believe that political and economic stability, increasing research funds, and fortifying the research infrastructure and laboratories are fundamental keys for more success.

Acknowledgments Work in the authors' lab was supported by a grant from the Science and Technology Development Fund (STDF), Egypt (grant no. 502).

\section{References}

Balkanci YD, Pehlivanoglu B, Bayrak S, Karabulut I, Karaismailoglu S, Erdem A (2012) The effect of hypercholesterolemia on carbacholinduced contractions of the detrusor smooth muscle in rats: increased role of L-type $\mathrm{Ca}^{2+}$ channels. Naunyn-Schmiedeberg's Arch Pharmacol 385:1141-1148

Coelho MM, Tegeder I, Michel MC (2011) Emerging country pharmacology: a 10-year perspective from Naunyn-Schmiedeberg's Archives of Pharmacology. Naunyn-Schmiedeberg's Arch Pharmacol 384:217-219

Dollery CT (2006) Clinical pharmacology - the first 75 years and a view of the future. Br J Clin Pharmacol 61(6):650-665

Haas LF (1999) Papyrus of Ebers and Smith. J Neurol Neurosurg Psychiatry 67:578

Hosseinzadeh H, Taiari S, Nassiri-Asl M (2012) Effect of thymoquione, a constituent of Nigella sativa L., on ischemia-reperfusion in rat skeletal muscle. Naunyn-Schmiedeberg's Arch Pharmacol 385: 503-508

Jembrek MJ, Gasparovic AC, Vukovic L, Vlainic J, Zarkovic N, Orsolic N (2012) Quercetin supplementation: insight into the potentially harmful outcomes of neurodegeneration prevention. NaunynSchmiedeberg's Arch Pharmacol 385:1185-1197

Khori V, Najafi SA, Alizadeh AM, Moheimani HR, Shakiba D, Alizadeh F, Nayebpour M (2012) Protective role of simvastatin on isolated rabbit atrioventricular node during experimental atrial fibrillation model: role in rate control of ventricular beats. Naunyn-Schmiedeberg's Arch Pharmacol 385:697-706

Kheir N, Zaidan M, Younes H, El Hajj M, Wilbur K, Jewesson PJ (2008) Pharmacy education and practice in 13 Middle Eastern countries. Am J Pharm Educ 72:133

Mahmoud MF, El Shazly SM, Barakat W (2012) Inhibition of TNF- $\alpha$ protects against hepatic ischemia-reperfusion injury in rats via NFKB dependent pathway. Naunyn-Schmiedeberg's Arch Pharmacol 385:465-471

Nader MA, El-Awady MS, Shalaby AA, El-Agamy DS (2012) Sitagliptin exerts anti-inflammatory and anti-allergic effects in ovalbumin- 
induced murine model of allergic airway disease. NaunynSchmiedeberg's Arch Pharmacol 385:909-919

Pang CY, Mak JW, Ismail R, Ong CE (2012) In vitro modulatory effects of flavonoids on human cytochrome P450 2C8 (CYP2C8). NaunynSchmiedeberg's Arch Pharmacol 385:495-502

Reid DM (1990) Cairo University and the making of modern Egypt. Cambridge University Press, Cambridge

Renno WM, Al-Maghrebi M, Al-Banaw A (2012) (-)-Epigallocatechin3 -gallate (EGCG) attenuates functional deficits and morphological alterations by diminishing apoptotic gene overexpression in skeletal muscles after sciatic nerve crush injury. Naunyn-Schmiedeberg's Arch Pharmacol 385:807-822
Savage-Smith E (1994) Islamic culture and the medical arts: a brochure to accompany an exhibition in celebration of the 900th anniversary of the oldest Arabic medical manuscript in the collections of the national library of medicine. University of Oxford, National Library of Medicine, Bethesda. (http://www.nlm.nih.gov/exhibition/islamic medical/islamic_12.html). Accessed 28 July 2013

van Noorden R (2012) 2012 in review. Nature 492:324-327

Votychik OI, Strutynskyi RB, Moibbenko OO, Shuba YM (2012) Effects of fluorine-containing opener of ATP-sensitive potassium channels, pinacidil-derivative flocalin, on cardiac voltage-gated sodium and calcium channels. Naunyn-Schmiedeberg's Arch Pharmacol 385: 1095-1102 